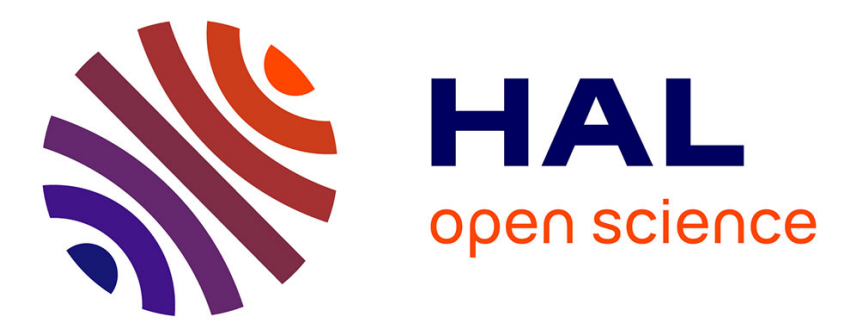

\title{
Damped dynamic response of strengthened beams by composite coats under moving force by FEM
}

Abdennacer Chemami, Youcef Khadri, Sabiha Tekili, El Mostafa Daya, Ali Daouadji, Zitouni Azari

\section{- To cite this version:}

Abdennacer Chemami, Youcef Khadri, Sabiha Tekili, El Mostafa Daya, Ali Daouadji, et al.. Damped dynamic response of strengthened beams by composite coats under moving force by FEM. Matériaux \& Techniques, 2018, 106 (2), pp.206. 10.1051/mattech/2018025 . hal-01915626

\author{
HAL Id: hal-01915626 \\ https://hal.science/hal-01915626
}

Submitted on 7 Nov 2018

HAL is a multi-disciplinary open access archive for the deposit and dissemination of scientific research documents, whether they are published or not. The documents may come from teaching and research institutions in France or abroad, or from public or private research centers.
L'archive ouverte pluridisciplinaire HAL, est destinée au dépôt et à la diffusion de documents scientifiques de niveau recherche, publiés ou non, émanant des établissements d'enseignement et de recherche français ou étrangers, des laboratoires publics ou privés. 


\title{
Damped dynamic response of strengthened beams by composite coats under moving force by FEM
}

\author{
Abdennacer Chemami ${ }^{1,}$, Youcef Khadri ${ }^{1}$, Sabiha Tekili ${ }^{1}$, El Mostafa Daya ${ }^{2}$, Ali Daouadji ${ }^{3}$, and Zitouni Azari ${ }^{4}$ \\ ${ }^{1}$ Département de génie mécanique, Laboratoire de Mécanique Industrielle, Université Badji Mokhtar, BP 12, Annaba 23000, \\ Algérie \\ ${ }^{2}$ Université de Lorraine, LEM3-Metz, Ile du Saulcy, 57045 Metz, France \\ 3 Laboratoire Sols-Matériaux-Structures Intégrité et Durabilité INSA, 69100 Villeurbanne Lyon, France \\ ${ }^{4}$ Laboratoire de Mécanique, Biomécanique, Polymère, Structures (LaBPS)-ENIM, 57078 Metz, France
}

Received: 11 May 2017 / Accepted: 16 May 2018

\begin{abstract}
This paper presents a numerical study of the free and damped forced vibration of simply-supported beams with composite coats subjected to a moving load by use of finite elements method. Three types of beam configurations, aluminum, composite and strengthened beam are investigated. The equation of motion of the beam is solved using the modal superposition method and integrated by applying the Newmark time integration procedure. Good agreements were achieved between the FEM and analytical solutions. The damped dynamic response, critical velocities and the dynamic amplification factor of the beam are calculated for different parameters such as the thickness ratio, the fiber orientation of the coat and damping ratio.
\end{abstract}

Keywords: dynamic beams / moving load / FEM / strengthened beam / composite coats

\begin{abstract}
Résumé. Réponse dynamique amortie des poutres renforcées par des couches en composites sous une force mobile en utilisant la MEF. Cet article présente une étude numérique des vibrations libres et forces amorties des poutres simplement appuyées avec des couches composites soumises à une force en mouvement en utilisant la méthode des éléments finis. Trois types de configurations de poutre sont étudiés, poutre en aluminium, en composite et poutre renforcée par matériaux composites. L'équation du mouvement de la poutre est résolue en utilisant la méthode de superposition modale et elle est intégrée en appliquant la technique de Newmark. De bons accords ont été conclus entre la MEF et les solutions analytiques. La réponse dynamique amortie, les vitesses critiques et le facteur d'amplification dynamique de la poutre sont calculés pour différents paramètres tels que le rapport d'épaisseur, l'orientation des fibres de la couche et le rapport d'amortissement.
\end{abstract}

Mots clés: dynamique des poutres / charge mobile / MEF / renforcement des poutres / couches composites

\section{Introduction}

The use of composite materials in modern engineering has increased considerably in recent years. As the composite materials offer many desirable structural properties such as lightweight and high strength, they are used to increase the rigidity of civil engineering structures such as girders, rails, crane and bridges for high speed trains. Thus, the composite materials are attached to these structures without any destruction. In the work [1], the observations of the fracture surfaces revealed the different modes of damages causing the material fracture and the lifetimes are

\footnotetext{
* e-mail: chem_nacer@yahoo.fr
}

characterized by the Wöhler curves. This study evidenced the influence of the reinforcement orientation on endurance of the studied material. The degradation of the rigidity modulus in fatigue for two types of sandwich materials, $\left[0_{4}\right]$ and $\left[0 / 90_{2} / 0\right]$ was determined from the deflection equation for the two sandwiches [2]. In this study, the experiments revealed that the modulus of the $\left[0_{4}\right]$ sandwich degraded faster than that of $\left[0 / 90_{2} / 0\right]$. The evolution of shear modulus in fatigue of both sandwiches is also described analytically using exponential and polynomial models. Many studies exist on the dynamic behavior of isotropic structures subjected to moving load in which the analytical and numerical methods are used [3-6]. However, the number of studies related to the vibration of beams with composite coats is relatively less [7-9]. Hamada et al. [7] 
studied the variations in natural frequencies and damping properties of laminated composite coated beams utilizing a numerical technique to compute the eigen parameters of coated laminated composite beams (sandwich structures).

Zibdeh et al. [8] examined the dynamic response of a simply supported beam coated with different fiber orientation of composite coats traversed by a random moving load. Tekili et al. [9] examined the free-vibration behavior of simply-supported laminated composite coated beams with different boundary conditions. Different definitions of stiffness parameters of composite structures are presented in numerous studies. The equivalent stiffness of the beams with composite coats has been calculated from the formulation of the Vison and Sierakowski [10] and Berthelot [11]. They use the behavior of composite beams as an equivalent isotropic behavior. Hajianmalecki and Qatu [12] showed that using equivalent modulus of elasticity of each lamina, one can get accurate results for static and dynamic analyses. The stiffness parameters of composite beams can be presented by a classical beam theory or Euler Bernoulli beam theory, where shear deformation and rotary inertia are negligible. Qatu and Iqbal [13] and Qatu and Elsharkawi [14] used classical beam theory to study vibration of straight cross-ply laminated beams. The theories considering shear deformation are called as Timoshenko beam theories $[15,16]$. The numerical methods such as the finite difference method and finite elements method are used in the analysis of the dynamic behavior of composite structures. Numayr [17] studied the free-vibration behavior of symmetrically laminated fiber-reinforced composite beams with different boundary conditions. The finite-difference method is used to solve the partial differential equations describing the freevibration motion. Kiral et al. [18] studied the dynamic behavior composite beam subjected to vertical moving force using a computer code of finite elements. In Kadivar et al. [19], the one dimensional finite elements based on classical lamination theory, first-order shear deformation theory, and higher-order shear deformation theory are developed to study the dynamic response of an unsymmetric composite laminated orthotropic beam. Mohebpour et al. [20] presented the free vibration and moving oscillator problems of isotropic and composite laminated beams using the finite element method. In other researches, they studied the dynamic behavior of the composite beam using analytical approximations. Kahya [21] presented the approximate analytical solution for the dynamic response of composites and with beams subjected to moving mass. For solving dynamic equations of composite beams a number of procedures, which can be found in the literature, are employed. In this study, the damped dynamic response of strengthened beams by composite coats under action of the moving loads at a constant speed has been investigated by use of finite element method with the Newmark integration method. For a large slenderness ratio, deformation due to effect of shear force is negligible as compared to deformation due to flexure. Therefore, here the classical beam theory suffices to accurately predict the stiffness parameters of composite coats. As the main goal of this study, the damped dynamic response of the composite beam is modeled as the Rayleigh damping which is widely used in structural dynamics. The effects of various parameters such as load speed and position,

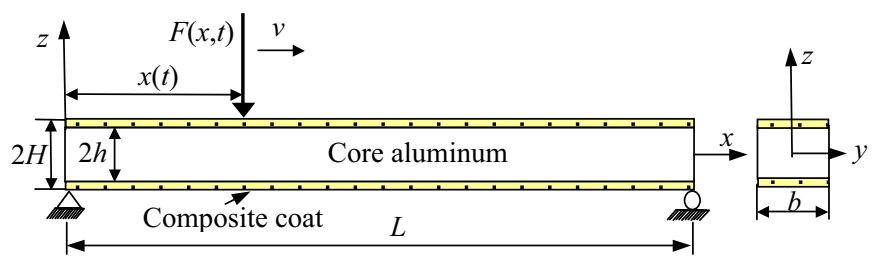

Fig. 1. A simply supported strengthened beam under a force moving.

the thickness ratio and fiber orientation of composite coats on natural frequencies mode and damped dynamic responses is parametrically studied.

\section{Theoretical formulation}

An aluminum beam is strengthened by composite coats made from composite material, carbon/epoxy and with a thickness $(\mathrm{H}-\mathrm{h})$, as shown in Figure 1. The core is made from an isotropic material aluminum, where $\mathrm{L}, \mathrm{b}$, and $2 \mathrm{H}$ are the length, the width and thickness of the beam, respectively.

According to classical beam theory, which was derived by [9], moment equation for unit length is obtained in the case of plane strain and in-plane forces of the symmetrical laminated beam as [11]:

$$
\left\{\begin{array}{l}
M_{x} \\
M_{y} \\
M_{x y}
\end{array}\right\}=\left[\begin{array}{ccl}
D_{11} & D_{12} & 0 \\
D_{12} & D_{22} & 0 \\
0 & 0 & D_{66}
\end{array}\right]\left\{\begin{array}{l}
\kappa_{x} \\
\kappa_{y} \\
\kappa_{x y}
\end{array}\right\}
$$

where $M_{\mathrm{x}}, M_{\mathrm{y}}$, and $M_{\mathrm{xy}}$, are the bending and twisting moments, and $\kappa_{x}, \kappa_{y}$, and $\kappa_{x y}$ are the curvatures of plate, which are defined by:

$$
\kappa_{x}=\frac{\partial \varphi_{x}}{\partial x}, \kappa_{y}=\frac{\partial \varphi_{y}}{\partial y}, \kappa_{x y}=\frac{\partial \varphi_{x}}{\partial y}+\frac{\partial \varphi_{y}}{\partial x}
$$

with $\varphi_{x}$ and $\varphi_{y}$ are rotations and the stiffness parameters are:

$$
D_{i j}=\frac{1}{3} \sum_{k=1}^{n}\left(z_{k}^{3}-z_{k-1}^{3}\right)\left(Q_{i j}^{\prime}\right)_{k}
$$

The beam theory makes the assumption that in the case of bending along $x$-direction, the bending and twisting moments $M_{\mathrm{y}}$ and $M_{\mathrm{xy}}$ are zero. The relation (1) and (2) thus lead to:

$$
M_{x}=D_{11} \kappa_{x}=-D_{11} \frac{\partial^{2} w}{\partial x^{2}}
$$

where

$$
D_{11}=\frac{1}{3} \sum_{k=1}^{n}\left(z_{k}^{3}-z_{k-1}^{3}\right)\left(Q_{11}^{\prime}\right)_{k}
$$

The reduced stiffness constant of a unidirectional or orthotropic layer, off its material directions is obtained by:

$$
Q_{11}^{\prime}=Q_{11} \cos ^{4} \theta+Q_{22} \sin ^{4} \theta+2\left(Q_{12}+Q_{66}\right) \sin ^{2} \theta \cos ^{2} \theta
$$


where $\theta$ is the angle between the principal laminate's direction and the axis of the beam.

The elastic constants $Q_{i j}$ in the principal material coordinate system are expressed as follows:

$$
\begin{aligned}
Q_{11}= & \frac{E_{11}}{1-\left(E_{22} / E_{11}\right) v_{12}^{2}}, Q_{22}=\frac{E_{22}}{E_{11}} Q_{11}, \\
& t Q_{12}=v_{12} Q_{11}, Q_{66}=G_{12}
\end{aligned}
$$

where $E_{11}, E_{22}, G_{12}$, and $v_{12}$ are the engineering parameters of the kth lamina.

Lastly, the beam theory makes the additional assumption that the deflection is a function of $x$ only: $w=w(x, t)$. So, the mode shape of beam only depends on the coordinate $x$. In the framework of the beam theory, in this case the fundamental equations of laminates are simplified as:

$$
\rho_{s} \frac{\partial^{2} w}{\partial t^{2}}-\frac{\partial^{2} M_{x}}{\partial x^{2}}=F(x, t)
$$

where $F(x, t)$ is load applied to the beam.

Equations (8) and (4) lead to:

$$
\rho_{s} \frac{\partial^{2} w}{\partial t^{2}}+D_{11} \frac{\partial^{4} w}{\partial x^{4}}=F(x, t)
$$

The equivalent mass per unit length of the sandwich beam is expressed as [9]:

$$
\rho_{s}=b \sum_{k=1}^{n} \rho_{k}\left(z_{k}-z_{k-1}\right)=2 b\left(\rho_{c} h+\rho_{f}(H-h)\right)
$$

where $\rho_{c}$ and $\rho_{f}$ are the densities of the core and faces of the beam, respectively.

\section{Finite elements model}

Beam elements are used to model the strengthened beam by composite coats. In order to simulate the moving load considered beam is composed of $(n)$ elements, with $(n+1)$ nodes, with concentrated force moving with constant velocity, $v=L / \tau$, where $\tau$ is the traveling time across the beam. The displacement vector of the finite element is defined by the degrees of freedom at the nodes. Two degrees of freedom per node, translation $\mathrm{w}$, along $\mathrm{x}$-axis and rotation $\theta$, about $\mathrm{y}$-axis are considered:

$$
\{q\}_{k}^{T}=\left\{\begin{array}{llll}
w_{i} & \theta_{i} & w_{i+1} & \theta_{i+1}
\end{array}\right\}
$$

For beam element with four degrees-of-freedom, the number of non-zero entries within external force vector will be four:

$$
\{F(x)\}=\left\{\begin{array}{llllllllllll}
0 & 0 & 0 & \cdots & f_{1}^{k} & f_{2}^{k} & f_{3}^{k} & f_{4}^{k} & \cdots & 0 & 0 & 0
\end{array}\right\}
$$

where $f_{i}^{k}(t),(i=1,2,3,4)$ represent the equivalent nodal forces and moments, which are given by the following equations:

$$
\left\{f_{i}^{k}(t)\right\}=F \times\left\{N_{i}\right\} \quad i=1,4
$$

where $N_{\mathrm{i}}(i=1.4)$ are shape functions of the beam element given by $[12,13]$ :

$$
\begin{aligned}
N_{1} & =1-3 \xi^{2}+2 \xi^{3}, N_{2}=l\left(\xi-2 \xi^{2}+\xi^{3}, N_{3}\right. \\
& =3 \xi^{2}-2 \xi^{3}, N_{4}=l\left(-\xi^{2}+\xi^{3}\right)
\end{aligned}
$$

where $\xi=x / l$. Using the mode superposition method and assume that:

$$
w(x, t)=\Phi(x) Y(t)
$$

where $\Phi(x)=\phi_{n}(n=1,2, \ldots, \infty)$ is the modal matrix, $Y$ $(t)=q_{n}(n=1,2, \ldots, \infty)$ is the generalized coordinate vector.

The stiffness and mass matrices of an element are obtained from elastic strain energy and kinetic energy of the laminated beam [11]:

$$
\begin{gathered}
U=\frac{1}{2} \int_{0}^{h} b D_{11}\left(\frac{d^{2} w}{d x^{2}}\right)^{2} d x=\frac{1}{2}\{q\}_{e}^{T}\left[k_{e}\right]\{q\}_{e} \\
T=\frac{1}{2} \int_{0}^{h} \rho_{s}\left(\frac{d w}{d x}\right)^{2} d x=\frac{1}{2}\{\dot{q}\}_{e}^{T}\left[k_{e}\right]\{\dot{q}\}_{e}
\end{gathered}
$$

The overall mass and stiffness matrices are obtained by assembling the element matrices. The equation of motion of structural system is represented as follows:

$$
[M]\{\ddot{q}(t)\}+[K]\{q(t)\}=\{F(t)\}
$$

where $\{\ddot{q}\},\{q\}$ are the acceleration and displacement vectors for beam, respectively.

The natural vibration properties of the structure are calculated by analyzing the system by free vibration, which means the equation of motion, is rewritten without external forces. The use of a harmonic function describing the temporal evolution of the displacement in the equation (18) gives the following algebraic function:

$$
\left([K]-\omega_{j}^{2}[M]\right) \phi=0
$$

where $\omega_{j}$ is the $j$-th natural frequency and $\varphi$ is the corresponding modal deflections. The roots of equation (19) are the characteristic values, which are equal to the squares of the natural frequencies of the modes.

The natural frequencies of the simply supported of a symmetric laminate beam are expressed analytically as [9]:

$$
\omega_{j}=\frac{j^{2} \pi^{2}}{L^{2}} \sqrt{\frac{1}{\rho_{s} D_{11}^{-1}}} \quad j=1,2, n
$$

The critical speed is:

$$
\mathrm{v}_{\mathrm{cr}}=\frac{\omega L}{2 \pi}
$$

The Rayleigh damping with constant damping ratio is used for dynamic analyses. The use of proportional damping provides information about the damped response 
of the considered structure, thus the damping matrix $[C]$ of structure is formed by the linear combination of matrices of mass $[M]$ and stiffness $[K]$ as:

$$
[C]=c_{0}[M]+c_{1}[K]
$$

where $c_{0}$ is the mass proportional damping coefficient and $c_{1}$ is the stiffness proportional damping coefficient.

If the damping ratios $\xi_{\text {a }}$ and $\xi_{\mathrm{b}}$ are associated with two specific fundamental frequencies $\omega_{\mathrm{a}}$ and $\omega_{\mathrm{b}}$, Rayleigh damping coefficients $c_{0}$ and $c_{1}$ can be evaluated by the solution of the equation (12):

$$
\left\{\begin{array}{l}
c_{0} \\
c_{1}
\end{array}\right\}=\frac{2 \omega_{a} \omega_{b}}{\omega_{a}^{2}-\omega_{b}^{2}}\left[\begin{array}{cc}
\omega_{a} & \omega_{b} \\
-1 / \omega_{a} & 1 / \omega_{b}
\end{array}\right]\left\{\begin{array}{l}
\xi_{a} \\
\xi_{b}
\end{array}\right\}
$$

The first two fundamental modes and associated natural frequencies are considered with the same damping ratios in order to calculate the damping coefficients $c_{0}$ and $c_{1}$.

The equation of motion with damping matrix is as follows:

$$
[K]\{q\}+[C]\{\dot{q}\}+[M]\{\ddot{q}\}=\{F(x, t)\}
$$

where $\{\dot{q}\}$ is the velocity vector of the beam. The differential equation (24) is solved by using the implicit time integration Newmark- $\beta$ method with parameters $\gamma=0.5$ and $\beta=0.25$.

\section{Numerical results and discussion}

A computer code based on the finite element method was developed and written in MATLAB in order to calculate the dynamic response of the beams. The material geometrical properties and physical dimensions of the beams are the same as reference [7]. The beam has length, $L=500 \mathrm{~mm}$, width $b=25 \mathrm{~mm}$, thickness $H=4 \mathrm{~mm}$ as show in Figure 1. The simply supported strengthened beam is under action of moving force, $F=100 \mathrm{~N}$. The number of the finite elements used in vibration analysis is 100 . Table 1 shows material properties for the face and core of the beam models used in the study. The material of the core is aluminum and faces are made from AS4/3501-6 Carbone/ Epoxy composite material (Fiber is AS4 Carbone and Matrix is 3501-6 Epoxy).

By varying the thickness and the material of the face sheet of the beams, it is possible to obtain a desired performance. Four configuration beams are considered in this study, the full aluminum beam, beam strengthened with composite of different thickness ratio $(h / H)$ and the full composite beam. The thickness of the aluminum core takes on the value of $h=4,3,2,1$ and $0 \mathrm{~mm}$, for a full aluminum beam $(h / H=1)$, the beam strengthened with $\mathrm{h} /$ $H=0.75,0.50$ and 0.25 and full composite beam $(h / H=0)$, respectively. The dynamic analyses are also performed for anisotropic aluminum beam for comparison purpose.

\subsection{Free vibration}

The strengthened beam, with thickness ratio, $h / H=0.75$ and a fiber orientation, $\theta=0^{\circ}$, is considered for validation of
Table 1. Material property for the coat and core of the beam.

\begin{tabular}{lcc}
\hline $\begin{array}{l}\text { Material } \\
\text { property }\end{array}$ & $\begin{array}{l}\text { Core } \\
\text { (aluminium) }\end{array}$ & $\begin{array}{l}\text { Coats } \\
\text { (carbon/epoxy) }\end{array}$ \\
\hline$\rho_{c, f}\left(\mathrm{~kg} / \mathrm{m}^{3}\right)$ & 2800 & 1580 \\
$E_{11}(\mathrm{GPa})$ & 70 & 147 \\
$E_{22}(\mathrm{GPa})$ & 70 & 9 \\
$G_{12}(\mathrm{GPa})$ & 27 & 5 \\
$v_{12}$ & 0.29 & 0.3 \\
\hline
\end{tabular}

Table 2. Comparison between the FE results and the analytical solution of the natural frequencies.

\begin{tabular}{lccccc}
\hline Mode & \multicolumn{5}{c}{ Natural frequency } \\
\cline { 2 - 6 } & 1 & 2 & 3 & 4 & 5 \\
\hline Analytic 98.3 & 393.2 & 884.7 & 1572.9 & 2457.6 \\
FEM & 98.3 & 3983.1 & 884.3 & 1571.4 & 2454.0 \\
Er (\%) & 0.0059 & 0.0238 & 0.0534 & 0.0950 & 0.1483 \\
\hline
\end{tabular}

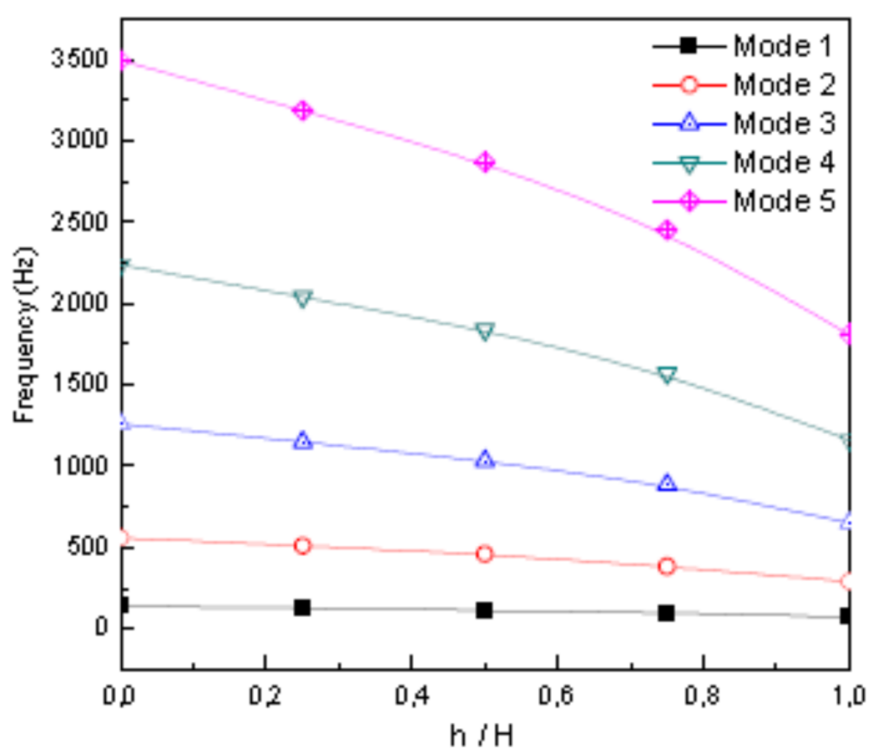

Fig. 2. First five frequencies of strengthened beam versus thickness ratio.

the present algorithm for free vibration. From Table 2 one observes that the first five natural frequencies computed by the FEM agree well with the analytical method (Eq. (20)).

The maximum relative error is of the order of $0.15 \%$ corresponding to the fifth frequency, the agreement between the finite element method and analytic solution is excellent.

The natural frequencies corresponding to mode 1, 2,3,4 and 5 are plotted in Figure 2. As can be seen from the figure, the natural frequencies are affected by the thickness ratio for high modes. However, for mode 1, the curve of the frequency is almost horizontal, it remains nearly indepen- 
dent of the thickness ratio, relatively compared to the higher modes. According to Figure 2, we note that the natural frequencies of the aluminum beam are almost

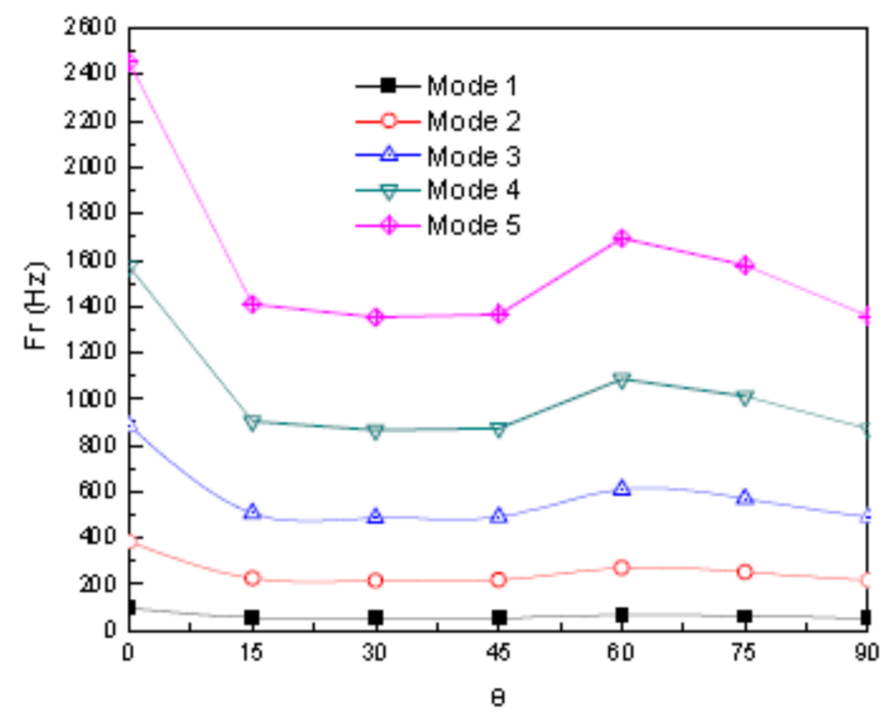

Fig. 3. First five frequencies of strengthened beam versus fiber orientation.

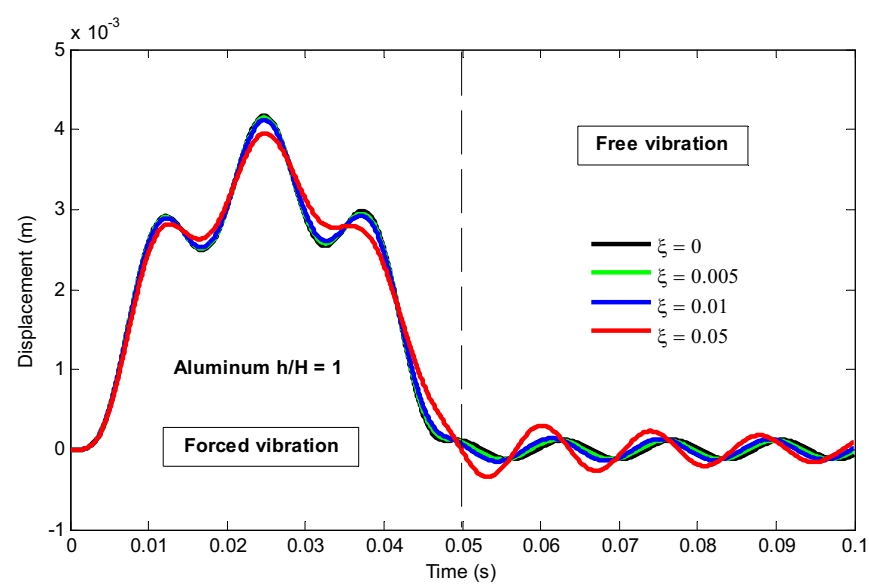

(a)

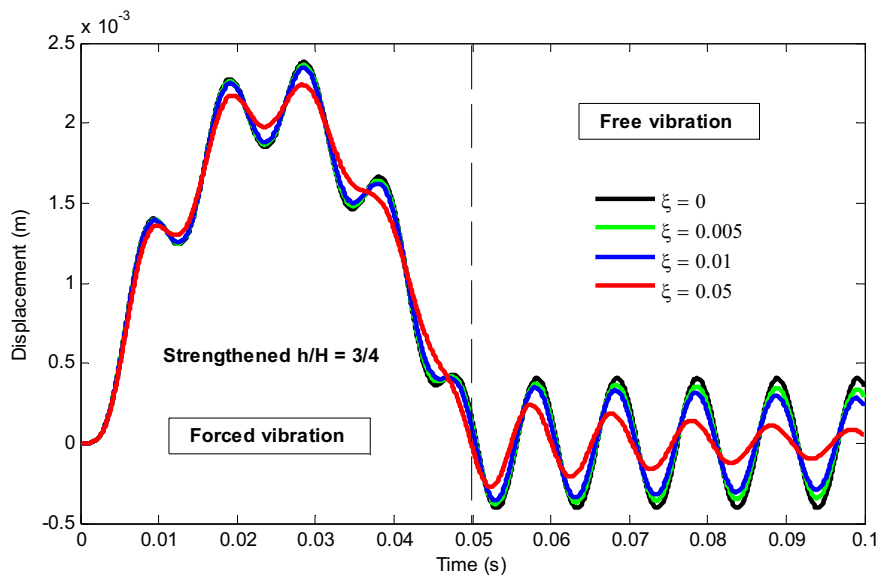

(b) identical to those of the composite beam and this is for low frequencies, however for the high frequencies, large difference is found. This difference is due to differences in stiffness of two materials.

The Figure 3 shows the variation of the first five natural frequencies of the strengthened beam versus the fiber orientation. In general, the frequency decreases with the increase in the fiber orientation. On the other hand, the frequency is almost constant (linear) for mode 1 compared to other modes. The maximum frequency is reached for the strengthened beam with $\theta=0^{\circ}$.

\subsection{Damped forced vibration}

The analyses of the forced vibration of the beam are estimated by superposition of the modes up to the 20th. The effect of damping ratio on the dynamic deflection of the beam is investigated with different configurations, full aluminum beam, strengthened beam and full composite beam and the composite coat with fiber orientation $\theta=0^{\circ}$. The dynamic response of simply supported beam can be separated by critical speed into two regions: undercritical and overcritical region. Figures 4 and 5 illustrate the damped displacement response of the beam for different

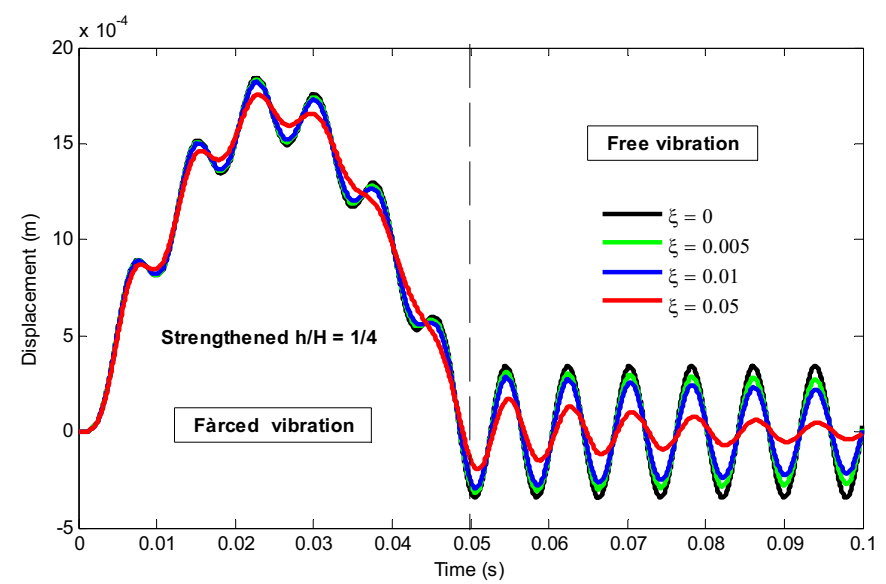

(c)

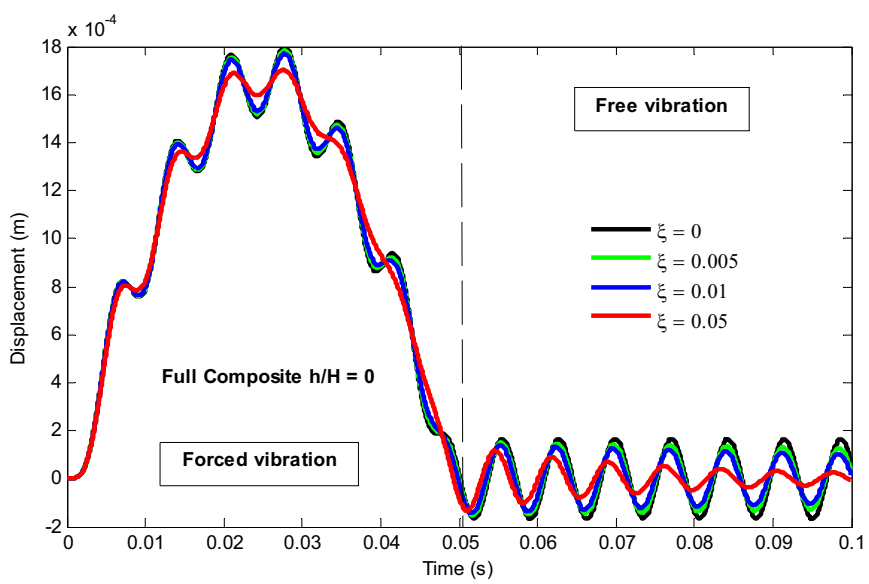

(d)

Fig. 4. Dynamic deflection of beam center with $\theta=0^{\circ}$ and velocity of moving load $v=10 \mathrm{~m} / \mathrm{s}$. (a) $h / H=1$, (b) $h / H=0.75$, (c) $h / H=0.25$, (d) $\mathrm{h} / \mathrm{H}=0$. 


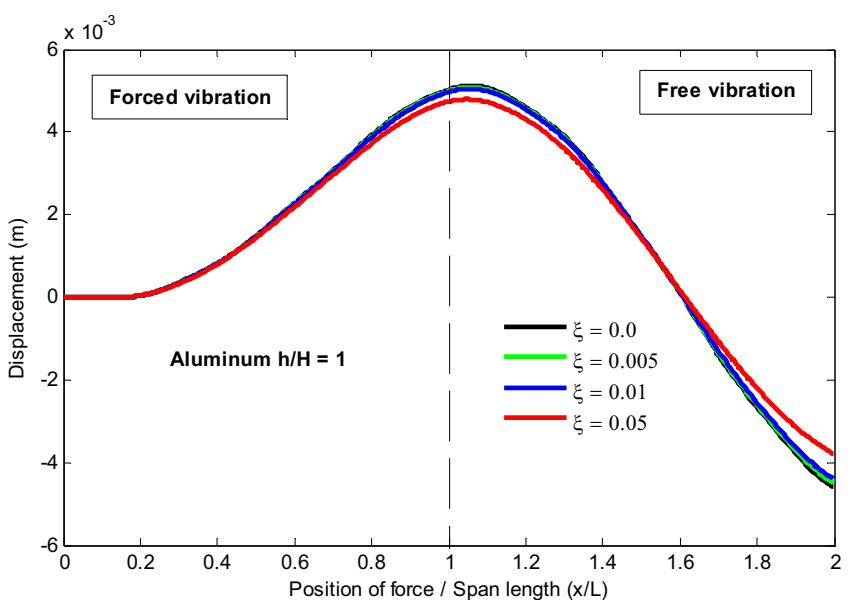

(a)

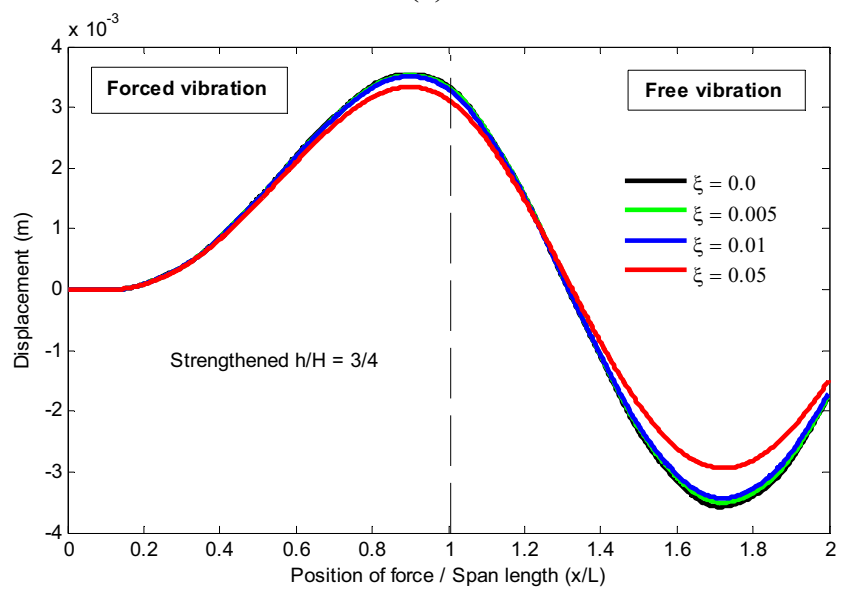

(b)

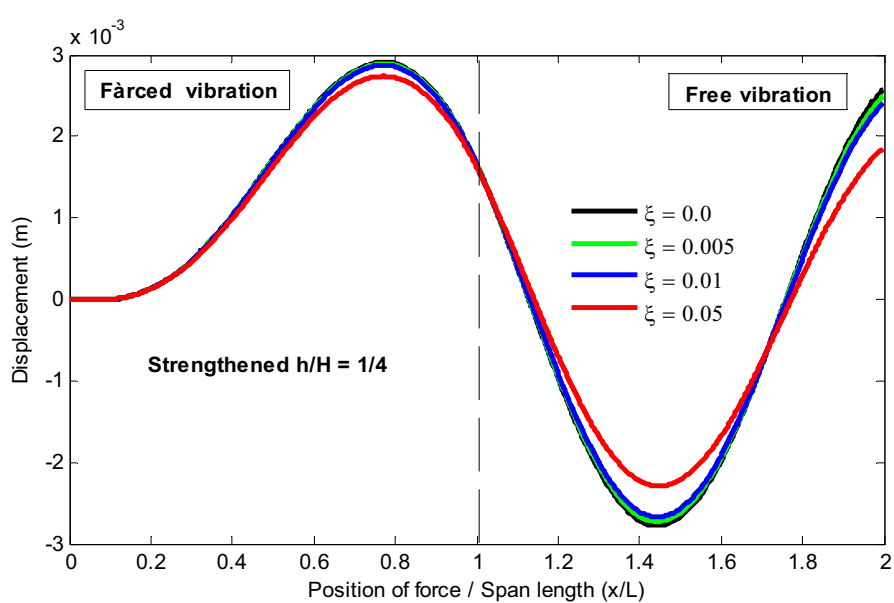

(c)

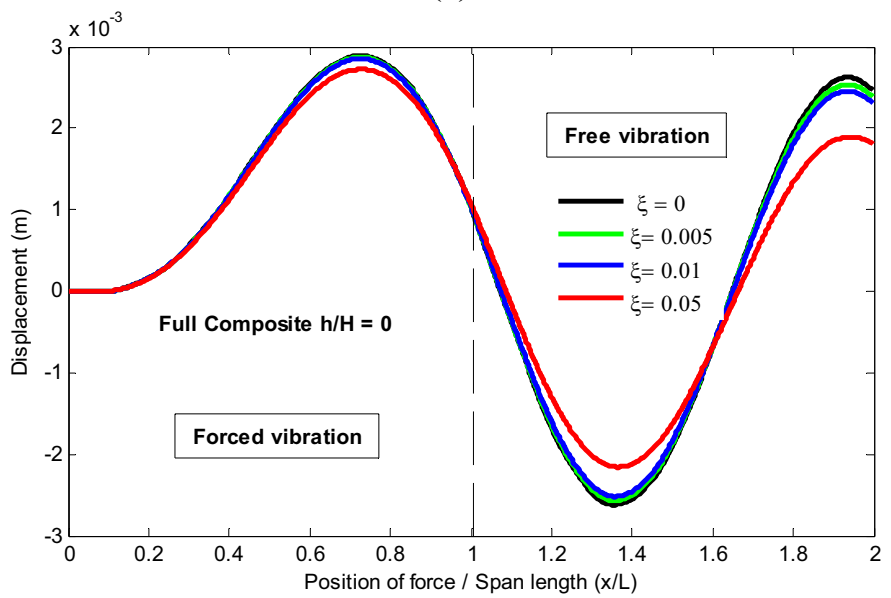

(d)

Fig. 5. Dynamic deflection of beam with $\theta=0^{\circ}$ and velocity of moving load. $v=80 \mathrm{~m} / \mathrm{s}$. (a) $h / H=1,(\mathrm{~b}) h / H=0.75,(\mathrm{c}) h / H=0.25,(\mathrm{~d})$ $h / H=0$.

configurations $h / H=1,0.75,0.25$ and 0 in the undercritical region $(v=10 \mathrm{~m} / \mathrm{s})$ and the overcritical region $(v=80 \mathrm{~m} / \mathrm{s})$ and the overcritical region $(v=80 \mathrm{~m} / \mathrm{s})$, respectively.

Figure 4 shows the time history of dynamic deflection vs. force when moving force passes the position of $0.5,0.58$, 0.44 and 0.56 of the beam length, for $h / H=1,0.75,0.25$ and 0 , respectively. Then, the maximum deflection of the beam center is 4.15, 2.4, 2.0 and $0.18 \mathrm{~mm}$.

One can see from Figure 4, when the force leaves the beam, in free vibration that the beam oscillates about its equilibrium position with progressively decreasing amplitude. The higher the damping ratio of the beam the higher the rate of reduction, however, the inverse trend is observed for aluminum beam $h / H=1$ (Fig. 4a). As can be expected, in forced vibration the dynamic deflections decrease with the increase in the damping ratio. The effect of damping ratio on the dynamic response is larger in free vibration. On the other hand, the effect of damping ratio is greater for case $h / H=0.75$ (Fig. 4c) than those obtained for other.

By referring to Figure 5, it can be concluded that the maximum deflection of beam has a delay respective to the position of moving load when the velocity is overcritical. In
Figure 5, the effect of damping ratio is almost the same for all configurations of the beam. The maximum deflection occurs when the force is near or after exit of the beam.

As shown in Figures 4 and 5, for the two cases undercritical and overcritical, the dynamic deflection of beam center decreases with the increase of the thickness of the composite coat. Because, when the thickness ratio increases, stiffness of the beam also increases, and thus the beam deflections decrease. The dynamic response of the beam to a moving load is defined in terms of the dynamic amplification factor (DAF), which is calculated for the mid-point of the beam. The DAF is defined as the ratio of the maximum dynamic displacement to the static displacement. The critical velocity is the velocity in which the maximum DAF occurs. From the static analysis of simply supported beam under the act of a concentrated force of $F_{0}$, the maximum static deflection is $F_{0} l^{3} / 48 D_{11}$.

The effect of damping ratio on the dynamic magnification factor of the beam with different configurations of the beam, $h / H=1,0.75,0.25$ and 0 is shown in Figure $6 \mathrm{a}-\mathrm{d}$, respectively. For all cases, in undercritical region the dynamic magnification factor is increased by increasing the 


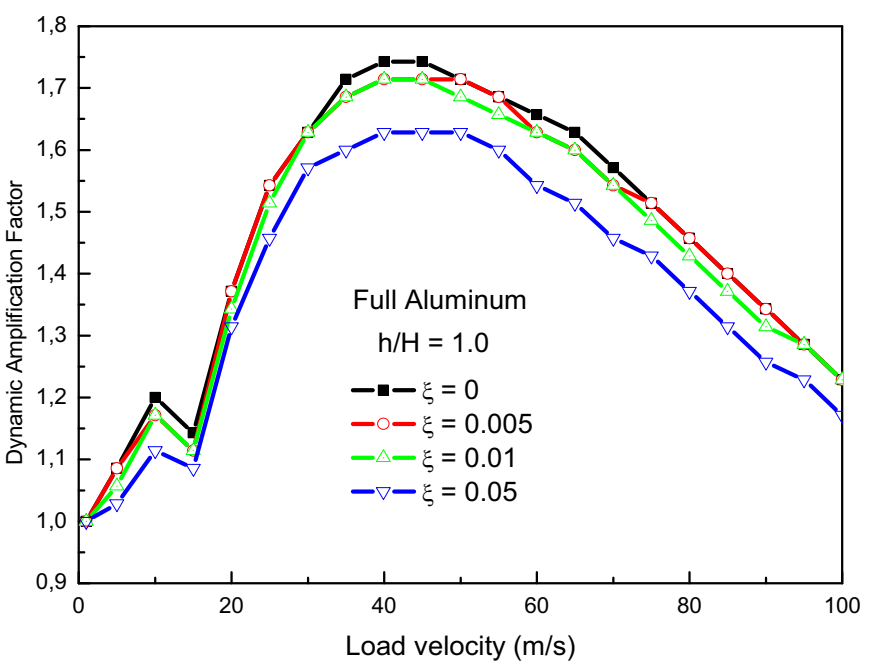

(a)

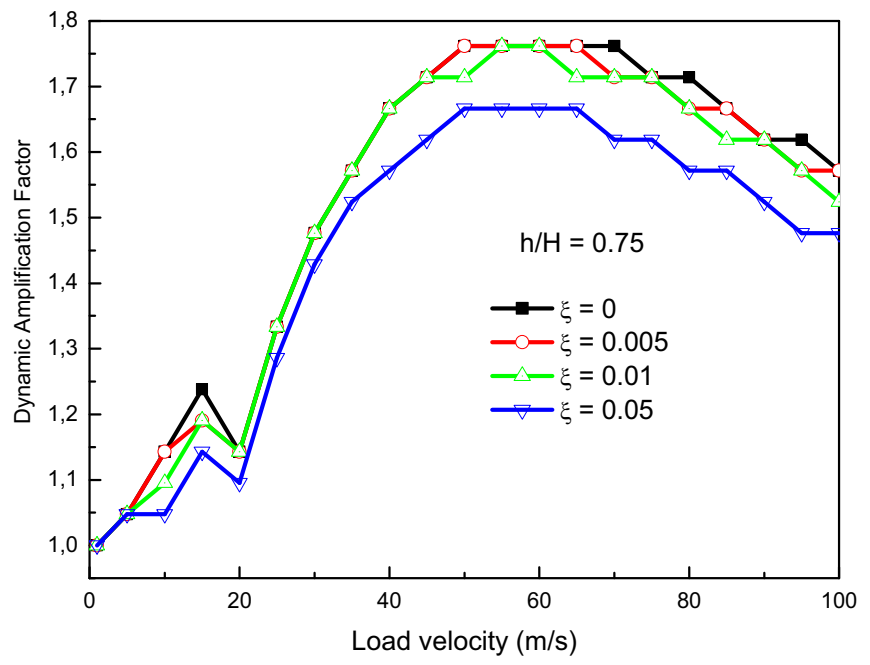

(b)

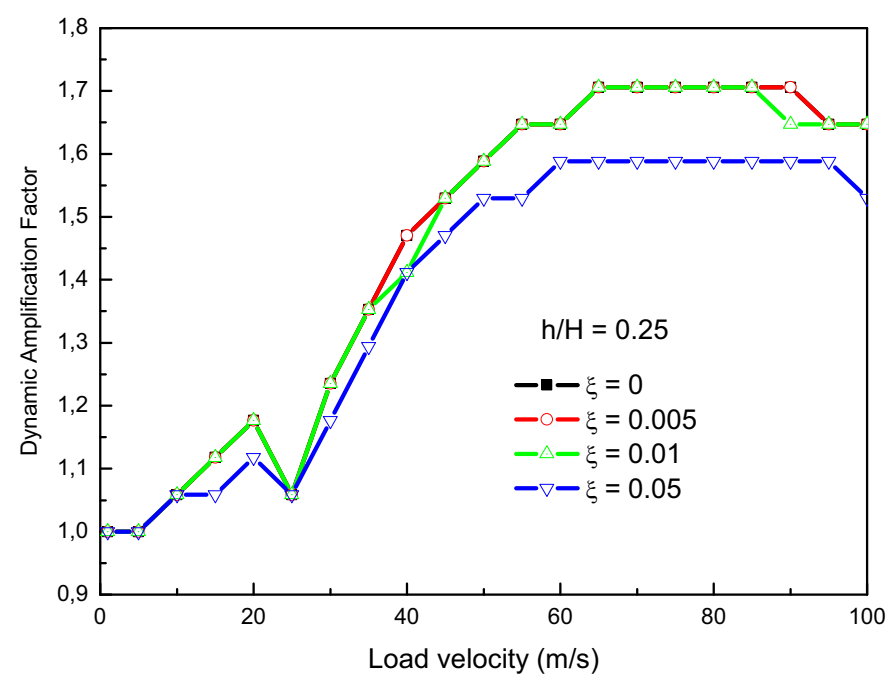

(c)

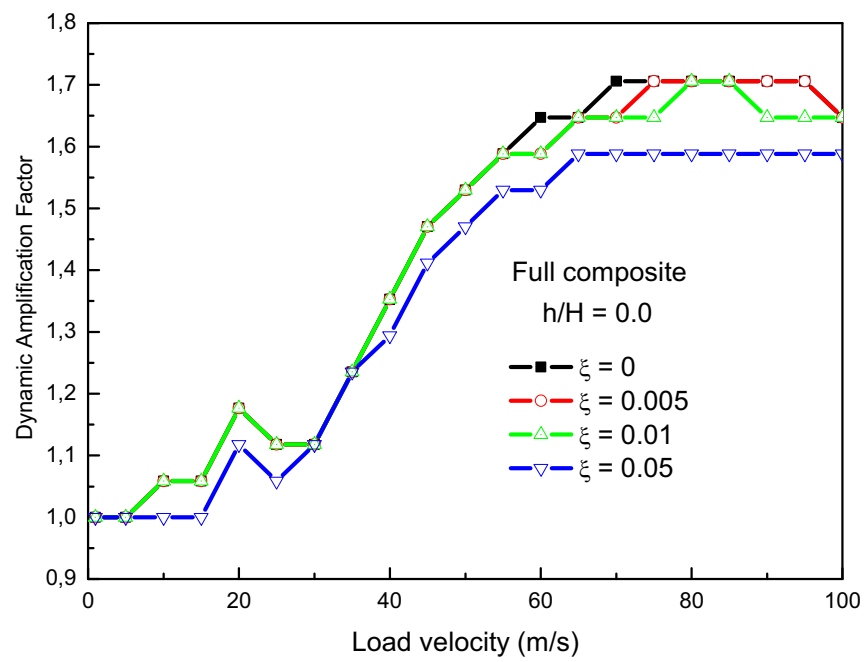

(d)

Fig. 6. DAF versus load velocity for different damping ratios and configuration beam. (a) $h / H=1,(\mathrm{~b}) h / H=0.75,(\mathrm{c}) h / H=0.25$, (d) $h / H=0$.

velocity of the moving load, but in the overcritical region dynamic magnification factor is decreased when the moving load velocity increases. It is shown in this figure for $h / H=1,0.75,0.25$ and 0 , the maximum DAF occurs at critical velocity $v \mathrm{c}=36.06, \quad 48.86,63.43, \quad 69.56 \mathrm{~m} / \mathrm{s}$, respectively. As shown from the Figure 6, the strengthened beam $h / H=0.75$ has greater dynamic amplification factor for values from 1.7619. It remains nearly independent of the load velocity in the moderate to high speed range (60 to $70 \mathrm{~m} / \mathrm{s}$ ) for $h / H=0.25$ (Fig. 6c) and full composite beam $h / H=0$ (Fig. 6c) with asymptotic value 1.58824 .

The DAFs decreased with the increase in the damping ratio, as can be expected. However, for the range of $v>v_{\mathrm{cr}}$, the damping ratio has a significant effect on DAF compared to lower speeds. For all cases, the effect of damping ratio is small on the critical velocity. However, the critical speed increased with the increase of the thickness of the composite coat, thus by using the composite coats; we can augment the critical velocity considerably.

The effect of damping ratio on the response dynamic of the beam with different orientation of fiber and $h / H=0.75$ is analyzed and shown in Figures 7 and 8 . Figure 7 shows the time history of dynamic deflections vs. force at velocity of moving load $v=15 \mathrm{~m} / \mathrm{s}$, for different coated beams, $\theta=0^{\circ}, 30^{\circ}, 60^{\circ}$ and $90^{\circ}$. It can be indicated that the maximum deflection at the beam center is 2.6, 9.8, 5.2 and $9.65 \mathrm{~mm}$, occurs when the moving force passes the position of $0.47,0.415,0.38$ and 0.41 of the beam length and for $\theta=0^{\circ}, 30^{\circ}, 60^{\circ}$ and $90^{\circ}$, respectively. The dynamic deflection of the beam coated by $0^{\circ}$ fiber orientation is relatively low compared with the others. This is due to the maximum equivalent stiffness at this orientation. Thereby the effect of damping ratio is largest in this case. 


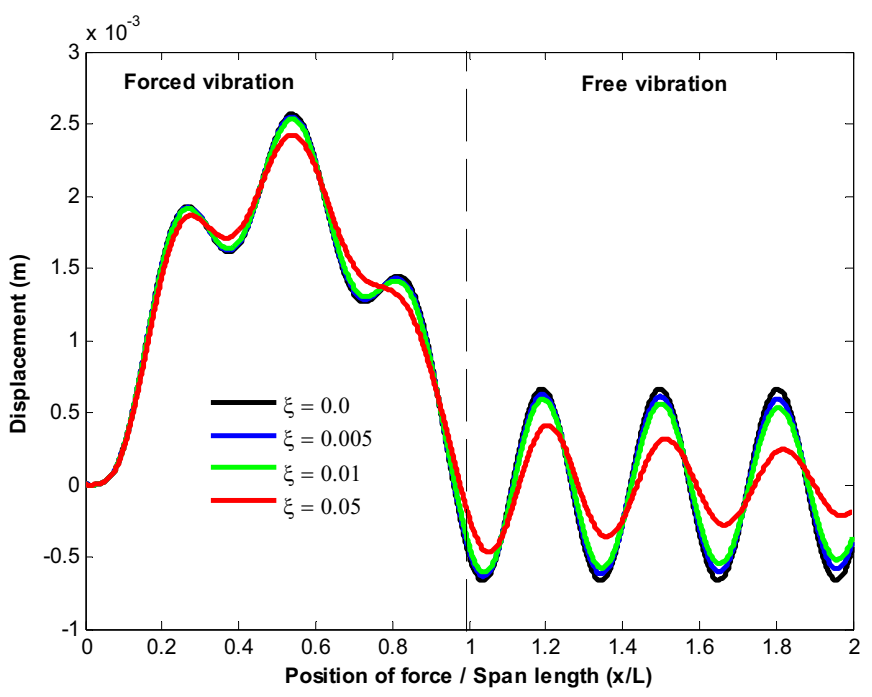

(a)

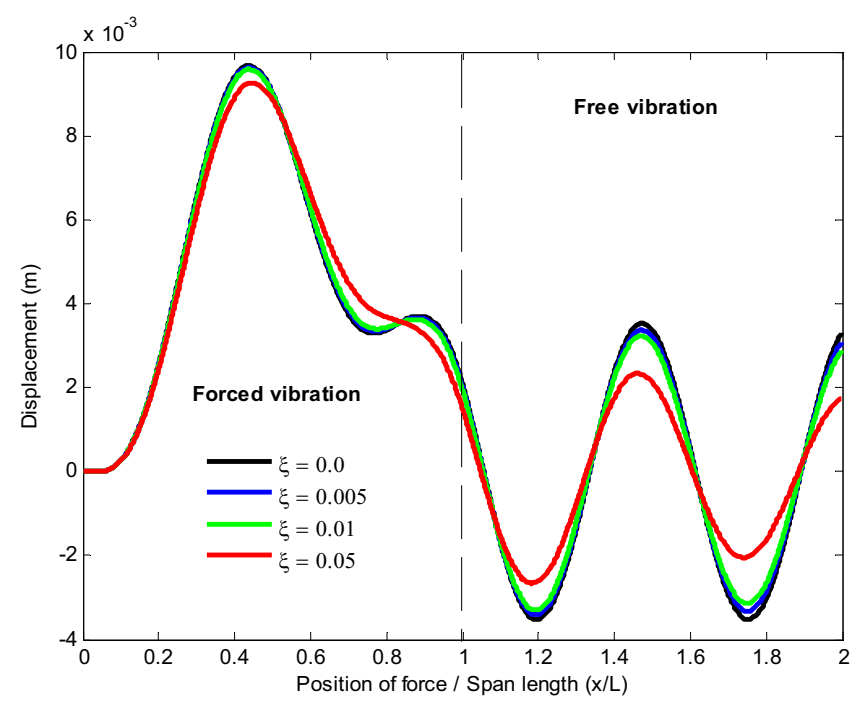

(b)

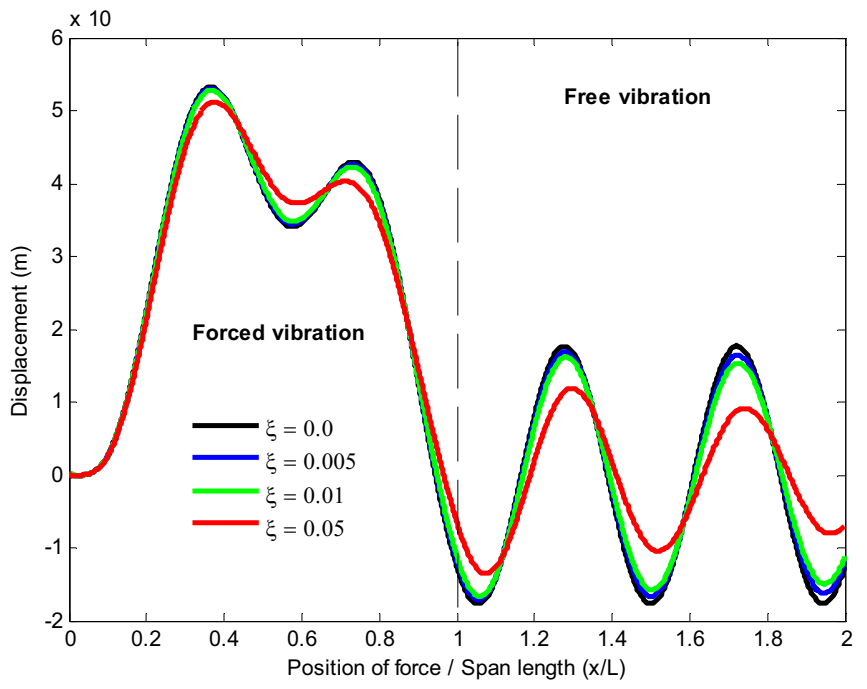

(c)

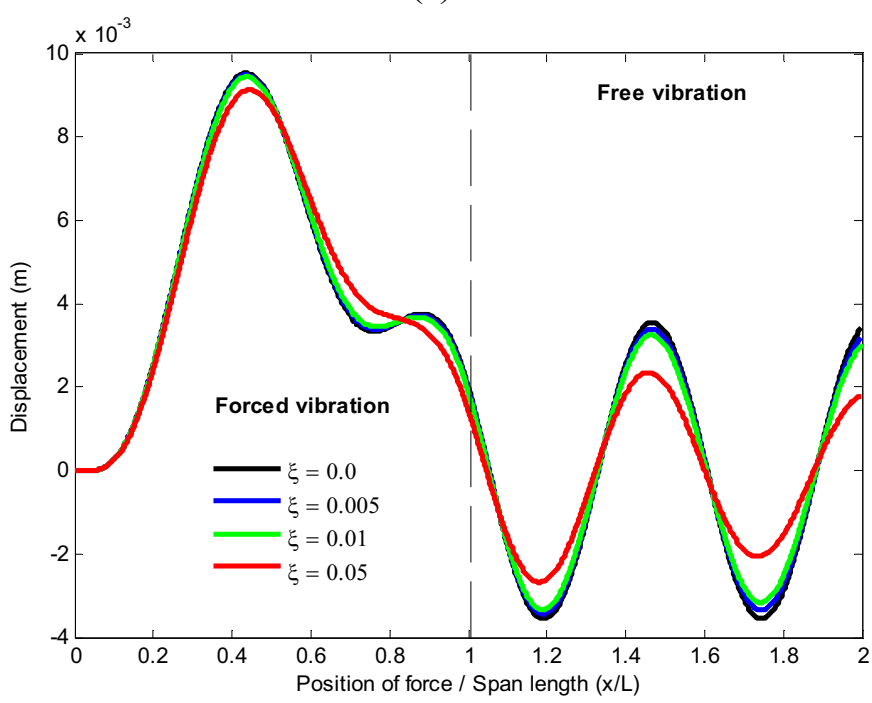

(d)

Fig. 7. Dynamic deflection of strengthened beam $h / H=0.75$ with velocity of moving load $v=15 \mathrm{~m} / \mathrm{s} .(\mathrm{a}) \theta=0^{\circ},(\mathrm{b}) \theta=30^{\circ},(\mathrm{c}) \theta=60^{\circ}$, (d) $\theta=90^{\circ}$.

The effect of damping ratio on the dynamic magnification factor of the beam with different fiber orientations, $\theta=0^{\circ}, 30^{\circ}, \quad 60^{\circ}$, and $90^{\circ}$ is shown in Figure $8 \mathrm{a}-\mathrm{d}$, respectively. It is shown in this figure for $\theta=0^{\circ}, 30^{\circ}, 60^{\circ}$ and $90^{\circ}$, the maximum DAF occurs at critical velocity $v \mathrm{c}=48.86,26.92,33.73,27.07 \mathrm{~m} / \mathrm{s}$, respectively. However, one expected that the critical velocities decrease as the fiber orientation increases.

From Figure 8 one observes that in undercritical region the damping ratio does not have a great effect on DAF. For damping ratio $\xi=0.0,0.005$, and 0.01 , the dynamic amplification factor values of strengthened beam are very close for all cases. The exponential decay in the dynamic amplification factor can be observed for the damping ratios greater than or equal to 0.05 .

\section{Conclusions}

The dynamic behavior of aluminum, full composite and strengthened aluminum beam under action of the moving loads at a constant speed has been investigated by use of finite element. The agreement between the finite element method and analytic solution is excellent. The effects of fiber orientation of the coat, thickness ratio and damping ratio are examined out through a parametric study. Based on obtained results followings are concluded: DAFs decrease with the increase in the damping ratio; however, for speed ranges above the critical speed, the damping ratio has a significant effect on DAF compared to lower speeds; the exponential decay in the dynamic amplification factor can be observed for the damping ratios greater than or 


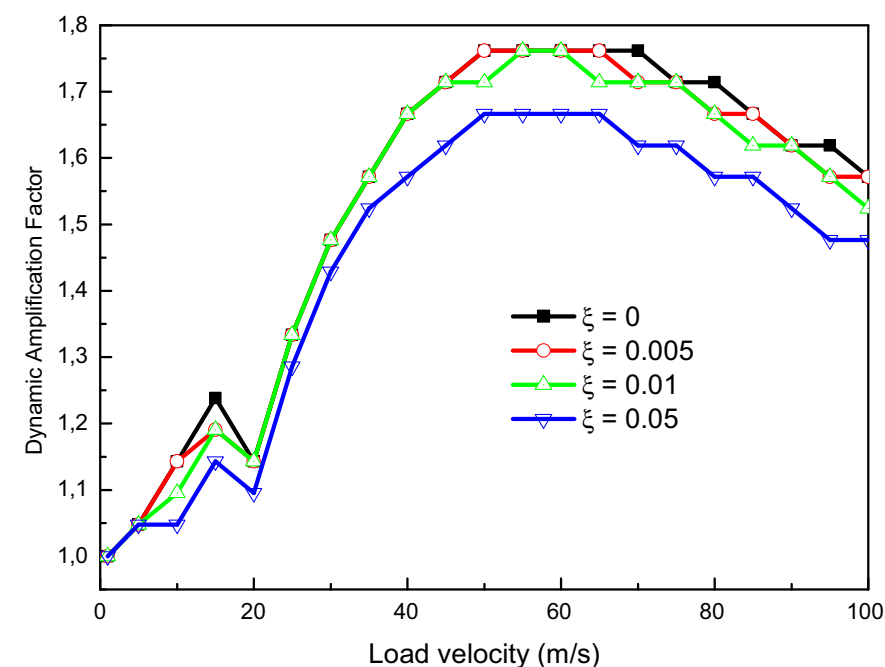

(a)

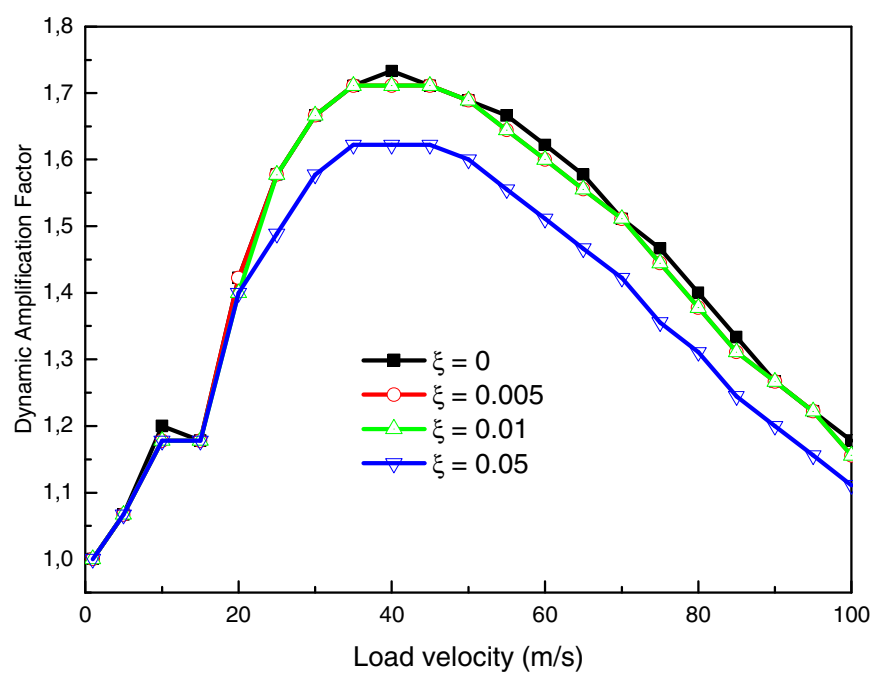

(c)
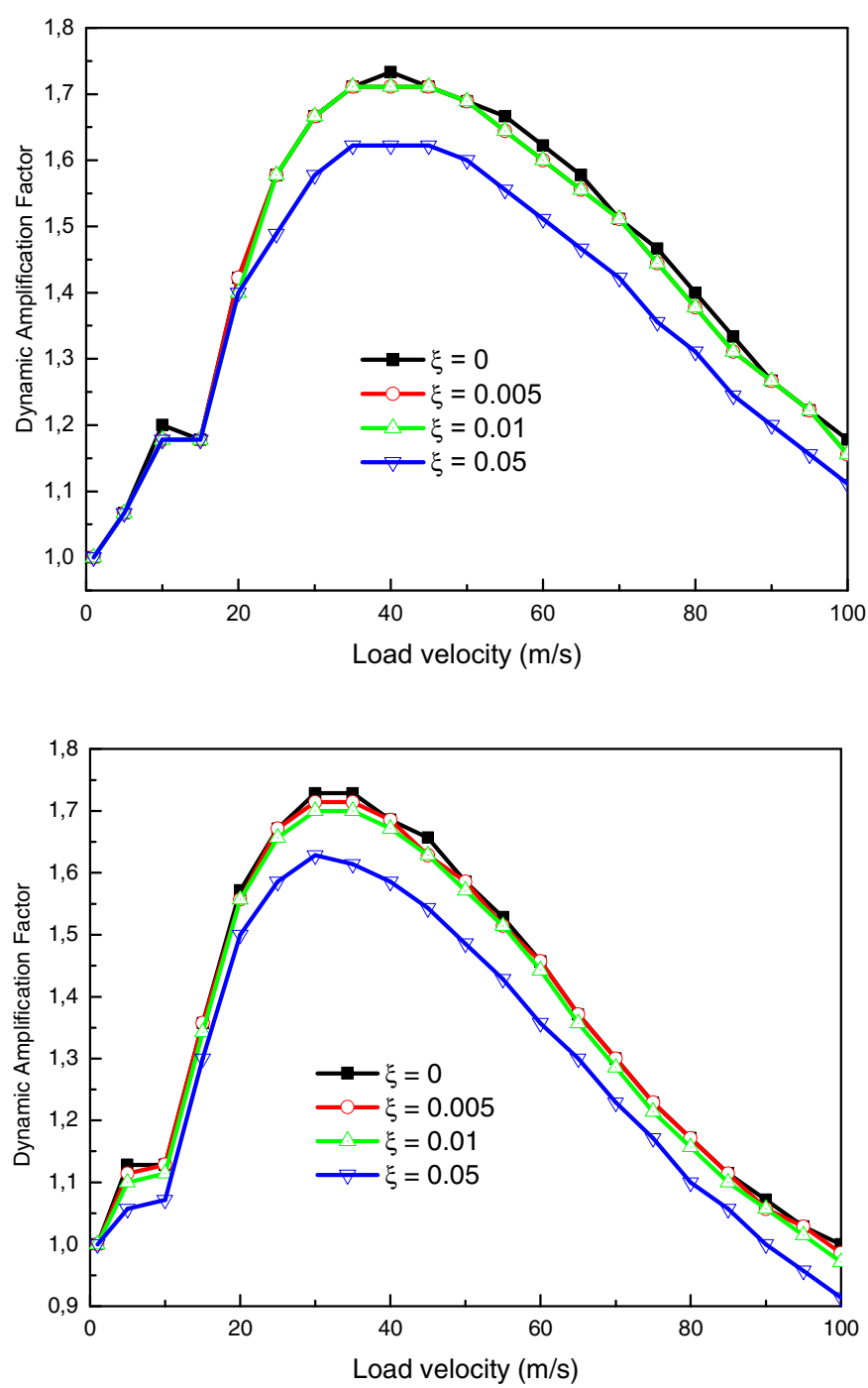

(d)

Fig. 8. DAF of the strengthened beam $h / H=0.75$ versus load velocity for different damping ratio. (a) $\theta=0^{\circ}$, (b) $\theta=30^{\circ}$, (c) $\theta=60^{\circ}$, (d) $\theta=90^{\circ}$.

equal to 0.05 ; the critical speed increased with the increase of the thickness of the composite coat and it decreased, in general, with the increase of fiber orientation; thus by using the composite coats; we can augment the critical velocity considerably

Acknowledgments. This work is one of the research projects of the Ministry for High Education and Scientific Research of Algeria. Code of project: J0301120130097. The National Commission for theEvaluation of the Research Projects gave a favorable opinion for three years (2013-2016).

\section{References}

1. A. Chemami, K. Bey, J. Gilgert, Z. Azari, Behaviour of composite sandwich foam-laminated glass/epoxy under solicitation static and fatigue, Composites: Part B 43, $1178(2012)$
2. K. Bey, K. Tadjine, R. Khelif, A. Chemami, M. Benamira, Z. Azari, Mechanical behavior of sandwich composites under three-point bending fatigue, Mech. Compos. Mater. 50(6), $1043(2015)$

3. J.M. Biggs, Introduction to structural dynamics, McGrawHill, New York ( NY, USA ), 1964

4. R.W. Clough, J. Penzien, Dynamics of structures, McGrawHill, New York, USA, 1993

5. Y. Khadri, S. Tekili, E.M. Daya, A. Daouadji, B. Merzoug, Effects of rail joints and train's critical speed on the dynamic behavior of bridges, Mechanika 19(1), 46 (2013)

6. Y. Khadri, S. Tekili, E.M. Daya, A. Daouadji, B. Merzoug, Dynamic analysis of train-bridge system and riding comfort of trains with rail irregularities, J. Mech. Sci. Technol. 27(4), $951(2013)$

7. A. Hamada, Vibration and damping analysis of beams with composite coats, Compos. Struct. 32, 33 (1995)

8. H.S. Zibdeh, M. Abu-Hilal, Stochastic vibration of laminated composite coated beam traversed by a random moving load, Eng. Struct. 25, 397 (2003) 
9. S. Tekili, Y. Khadri, B. Merzoug, Free vibration analysis of the strengthened beams by composite coats, Adv. Mater. Res. 716, 595 (2013)

10. J.R. Vinson, R.L. Sierakowski, The behavior of structures composed of composite materials, Dordrecht, Martinus Nijhoff, The Netherlands, 1989

11. J.-M. Berthelot, Dynamic of composite materials and structures, ISMANS, Institute for Advanced Materials and Mechanics, Le Mans, France, 2010

12. M. Hajianmaleki, M.S. Qatu, Mechanics of composite beams, in: P. Tesinova (Ed.), Advances in composite materialsanalysis of naturally and man-made materials, InTech Publishing Company, Croatia, 2011, pp. 527-546

13. M.S. Qatu, J. Iqbal, Transverse vibration of two-segment cross-ply composite shafts with a lumped mass, Compos. Struct. 92(5), 1126 (2010)

14. M.S. Qatu, A.A. Elsharkawi, Vibration of laminated composite arches with deep curvature and arbitrary boundaries, Comput. Struct. 47(2), 305 (1993)

15. C. Mei, Free and forced wave vibration analysis of axially loaded materially coupled composite Timoshenko beam structures, J. Vib. Acoust. 127, 519 (2005)
16. I.K. Silverman, Natural frequencies of sandwich beams including shear and rotary effects, J. Sound Vib. 183, 547 (1995)

17. K.S. Numayr, M.A. Haddad, A.F. Ayoub, Investigation of free vibrations of composite beams by using the finite-difference method, Mech. Compos. Mater. 42(3), 19 (2006)

18. B.G. Kiral, Z. Kiral, Effect of elastic foundation on the dynamic response of laminated composite beams to moving loads, J. Reinf. Plast. Comp. 28, 913 (2009)

19. M.H. Kadivar, S.R. Mohebpour, Finite element dynamic analysis of unsymmetric composite laminated beams with shear effect and rotary inertia under the action of moving loads, Finite Elem. Anal. Des. 29, 259 (1998)

20. S.R. Mohebpour, A.R. Fiouz, A.A. Ahmadzadeh, Dynamic investigation of laminated composite beams with shear and rotary inertia effect subjected to the moving oscillators using FEM, Compos. Struct. 93, 1118 (2011)

21. V. Kaha, A.S. Mosallam, Dynamic analysis of composite sandwich beams under moving mass, KSU, J. Eng. Sci. 14(1), $231(2011)$

Cite this article as: Abdennacer Chemami, Youcef Khadri, Sabiha Tekili, El Mostafa Daya, Ali Daouadji, Zitouni Azari, Damped dynamic response of strengthened beams by composite coats under moving force by FEM, Matériaux \& Techniques 106, 206 (2018) 